Bull. Chem. Soc. Ethiop. 2021, 35(1), 17-31.

(c) 2021 Chemical Society of Ethiopia and The Authors

ISSN 1011-3924

DOI: https://dx.doi.org/10.4314/bcse.v35i1.2

Printed in Ethiopia

Online ISSN 1726-801X

\title{
DEVELOPMENT AND VALIDATION OF A SINGLE HPLC METHOD FOR THE DETERMINATION OF THIRTEEN PHARMACEUTICALS IN BULK AND TABLET DOSAGE FORM
}

\author{
Bisratewongel Tegegne ${ }^{1,2,3}$, Bhagwan Singh Chandravanshi ${ }^{1 *}$, Feleke Zewge ${ }^{1}$, Letitia Pillay ${ }^{2}$ and \\ Luke Chimuka $^{2}$ \\ ${ }^{1}$ Department of Chemistry, College of Natural Sciences, Addis Ababa University, P.O. Box \\ 1176, Addis Ababa, Ethiopia \\ ${ }^{2}$ Molecular Sciences Institute, University of Witwatersrand, Private Bag X3, Johannesburg \\ 2050, South Africa \\ ${ }^{3}$ Department of Chemistry, College of Natural Sciences, Bahir Dar University, P.O. Box 79, Bahir \\ Dar, Ethiopia
}

(Received March 14, 2020; Revised February 22, 2021; Accepted March 13, 2021)

\begin{abstract}
The aim of this study was to develop and validate a high performance liquid chromatography (HPLC) method for the determination of thirteen selected pharmaceutical compounds (metformin, amoxicillin, chloroquine, theophylline, trimethoprim, caffeine, norfloxacin, ciprofloxacin, acetylsalicylic acid, doxycycline hyclate, metronidazole, albendazole and cloxacillin) in bulk and tablet dosage form. Chromatographic separation using a Kromasil $\mathrm{C}_{18}$ column, gradient elution with aqueous formic acid $(0.1 \%)$, methanol and acetonitrile, a UV absorption wavelength of $250 \mathrm{~nm}$ and a mobile phase flow rate of $1 \mathrm{~mL} / \mathrm{min}$ over a $22 \mathrm{~min}$ run time was optimized for complete separation of the selected target compounds. The method was validated and results for: linearity, precision, sensitivity, accuracy, specificity, suitability and method robustness were obtained and met the ICH guidelines. Calibration curve correlation coefficients ranged from $0.9985-0.9998$ and the percentage relative standard deviations for repeated analysis was below 5\%, indicating acceptable method precision. The limits of detection (LODs) and quantification (LOQs) ranged from $0.020-0.27 \mu \mathrm{g} / \mathrm{L}$ and $0.080-0.91 \mu \mathrm{g} / \mathrm{L}$, respectively. The accuracy study yielded recoveries in the ranges $86.0-102 \%$ for pure compounds and $90.9-106 \%$ for compounds in tablet dosage form. The method is robust for small or deliberate changes to the chromatographic parameters and found to be appropriate for analysis of tablets for the determination of the thirteen pharmaceuticals.
\end{abstract}

KEY WORDS: Pharmaceuticals, Bulk determination, Tablet dosage, High performance liquid chromatography, Method development, ICH guidelines

\section{INTRODUCTION}

Pharmaceuticals are synthetic or natural chemicals that are used extensively in human and veterinary medicine to prevent illness. They are also used as growth promoters that contain active ingredients designed to have pharmacological effects and confer significant benefits [1, 2]. After administration, a part of the consumed pharmaceuticals is excreted as metabolites and unchanged parent compounds largely through the urine and feces [3]. Classification of pharmaceuticals into various classes may be based on their pharmacological properties, such as their therapeutic effects. Those selected for this study are frequently prescribed drugs that are also detected in the environment.

Antibiotics are natural, semi-synthetic or synthetic drugs used as antibacterial, antifungal or anti-parasitic agents and are important medicines [4]. Widely used antibiotics include amoxicillin (AMOX), which is used to combat bacterial infections [5], and ciprofloxacin (CIP) a synthetic fluoroquinolone derivative with broad-spectrum activity against many pathogenic gram-positive bacteria [6]. Cloxacillin (CLA) belongs to the semi-synthetic $\beta$-lactam antibiotics

${ }^{*}$ Corresponding author. E-mail: bscv2006@yahoo.com

This work is licensed under the Creative Commons Attribution 4.0 International License 
used against staphylococci that produce beta-lactamas [7], while doxycyclinehyclate (DOXH), a broad spectrum tetracycline antibiotic with a large range of antibacterial activities [8]. A member of the fluoroquinolones third-generation antibiotics, norfloxacine (NOR), is used for the treatment of diseases caused by Campylobacter, Escherichia coli, Shigella and Vibrio cholera and used to treat gonorrhea and urinary tract infection [9]. The antibiotic trimethoprim (TMP) is used for protozoal infections [10], while metronidazole (MTZ) is prescribed for treatment and prophylaxis of anaerobic bacterial infections and specific bacterial infections [11].

Anthelminthics are drugs that are used to eject parasitic worms from the gastro-intestinal tract by either stunning or killing them [12]. Albendazole (ABZ) is one of several broadspectrum benzimidazole parasiticides used for treatment of parenchymal neurocysticercosis [13].

Anti-malarial drugs such as chloroquine (CHQ) are used for treating fever caused by malaria. Chloroquine is also prescribed to decrease the symptoms of rheumatoid arthritis and to treat systemic and discoidlupus erythematosus in adults [14].

Nonsteroidal anti-inflammatory drugs (NSAIDs) are used for treatment of fever, pain and inflammation. Acetyl salicylic acid (ASA), also known as aspirin, with the chemical name 2acetoxybenzoic acid, is one of the most widely used drugs in the world and exerts analgesic, antipyretic and anti-inflammatory effects $[15,16]$.

Central nervous system stimulants are a group of drugs that produce an increase in mental and motor activity. 1,3,7-Trimethylxanthine, commonly referred to as caffeine (CAF) acts as a stimulant psychotrope and as a mild diuretic [17], while theophylline (THP) displays antiinflammatory activities by inhibiting the activity of CD4 lymphocytes in vitro and through mediator release from mast cells [18].

Anti-diabetic metformin (MET) is used in the treatment of diabetes mellitus II, since it suppresses the production of hepatic glucose, and thus attenuates hyperglycemia [19].

Many authors have described the determination of pharmaceuticals in pure, tablet dosage form and real sample using a range of analytical techniques. Analytical techniques including liquid chromatography (LC) and gas chromatography (GC) are commonly employed for the separation and determination of compounds in mixtures, but liquid chromatography is mostly used to determine pharmaceuticals, since they are mostly non-volatile [20, 21]. Liquid chromatographic methods for amoxicillin [22], alebendazole [23], chloroquine [24], acetylsalicylic acid [16], caffeine [25], metronidazole [26], theophylline [27] and ciprofloxacin [28] have been reported. Spectrophotometric methods for amoxicillin [29], cloxacilln [30], ciprofloxacin [31], trimethoprim [32], albendazole [23], chloroquine [33], metronidazole [26] and for metformin [34] has been reported. Electrochemical methods for metronidazole [35], caffeine and theophylline [36], albendazole [37] and acetylsalicylic acid [38]; a kinetic method for amoxicillin [5] and a method using chemiluminescence for norfloxacin [39] are available in literature.

To the best of our knowledge there is no single HPLC method reported for the simultaneous determination of these selected pharmaceutical compounds of different therapeutic classes. This study attempts to develop a simple, accurate, precise and stable analytical chromatographic method, which can separate and determine thirteen selected pharmaceutical drugs simultaneously in a single optimized method in bulk and commercial tablet dosage form. The proposed method has been developed and validated as per the ICH guidelines for the analysis. Developing such an analytical method is more cost-effective than changing parameters for each analyte for the analysis of real samples. The developed method is suitable for laboratories that are not equipped with highly specialized state-of-the-art instrumentation. The method will still give a sufficiently accurate determination of the selected compounds. 


\section{EXPERIMENTAL}

\section{Chemicals, reagents and equipment}

All the chemicals used for method development were analytical grade. The HPLC grade methanol (>99\%) and HPLC grade acetonitrile (>99.9\%) were from Fisher Scientific (UK), the formic acid $(>96 \%)$ from Sigma Aldrich (Germany) and acetic acid $(99 \%)$ from Fisher Chemicals (UK). Ultra-pure water used throughout the study was generated using a Millipore system (Direct-Q 3 UV with pump, South Africa). Pharmaceutical standard compounds (assigned purity $\geq 99 \%$ ), listed in Table 1, were a kind donation from Addis Pharmaceuticals (Adigrat, Ethiopia) and tablets containing the target active compound were purchased from the local market in Addis Ababa, Ethiopia. Chromatographic separation was performed on an Agilent HPLC 1260 Series equipped with quaternary pump, auto sampler and diode array detectorfrom Agilent Technologies (Singapore, Germany). Data acquisition and processing were accomplished with LC Chemstation software (Agilent Technologies).

Table 1. Selected pharmaceuticals of different therapeutic classes used for method development.

\begin{tabular}{|c|c|c|c|c|}
\hline $\begin{array}{l}\text { Therapeutic } \\
\text { class }\end{array}$ & $\begin{array}{l}\text { Molecular } \\
\text { formula }\end{array}$ & $\begin{array}{l}\text { Molecular weight } \\
(\mathrm{g} / \mathrm{mol})\end{array}$ & Structure of the compound & $\begin{array}{c}\text { Maximimum absorption } \\
\text { wavelength, } \lambda_{\max }(\mathrm{nm})\end{array}$ \\
\hline Antibiotics & & & & \\
\hline Amoxicillin & $\mathrm{C}_{16} \mathrm{H}_{25} \mathrm{~N}_{3} \mathrm{O}_{7} \mathrm{~S}$ & 365.5 & & 335 \\
\hline Ciprofloxacin & $\mathrm{C}_{17} \mathrm{H}_{18} \mathrm{FN}_{3} \mathrm{O}_{3}$ & 331.3 & & 280 \\
\hline Cloxacillin & $\mathrm{C}_{19} \mathrm{H}_{19} \mathrm{ClN}_{3} \mathrm{NaO}_{6} \mathrm{~S}$ & 435.8 & & 254 \\
\hline Doxycyclinehyclate & $\mathrm{C}_{22} \mathrm{H}_{24} \mathrm{~N}_{2} \mathrm{O}_{8}$ & 444.4 & & 273 \\
\hline Norfloxacin & $\mathrm{C}_{16} \mathrm{H}_{18} \mathrm{FN}_{3} \mathrm{O}_{3}$ & 319.3 & & 273 \\
\hline
\end{tabular}




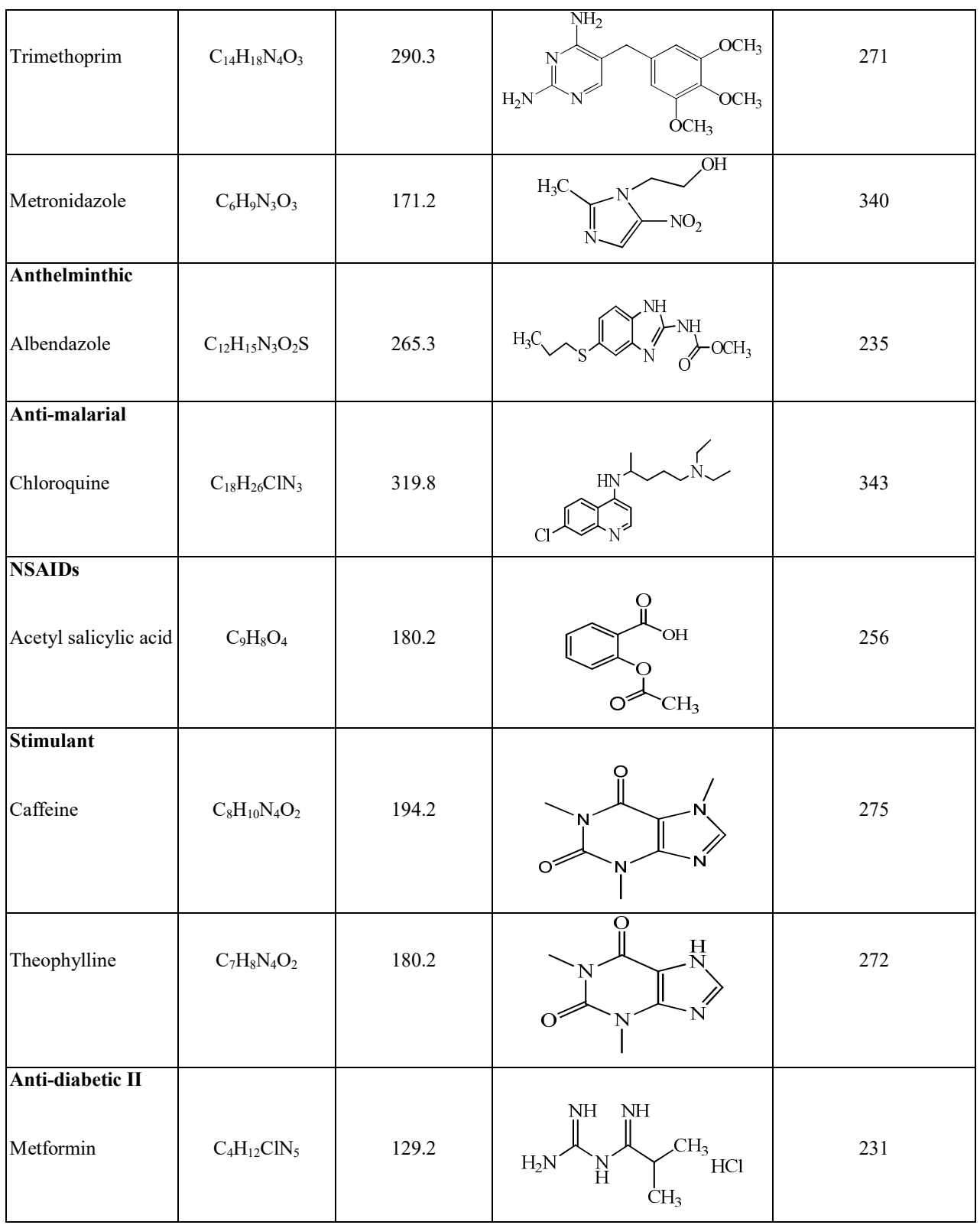

\section{Chromatographic separation}

Chromatographic separation of the thirteen selected pharmaceutical compounds was achieved using a Kromasil $\mathrm{C}_{18}, 5 \mu \mathrm{m}(4.6 \mathrm{~mm} \times 150 \mathrm{~mm} \times 5 \mu \mathrm{m})$ column (Sigma Aldrich, (Stockholm, Sweden) held at ambient temperature. A combination of $0.1 \%$ aqueous formic acid, acetonitrile and methanol was used as mobile phase at a flow rate of $1 \mathrm{~mL} / \mathrm{min}$. The detector was set to 
detect at $250 \mathrm{~nm}$ UV absorbance. An aliquot of $10 \mu \mathrm{L}$ of a mixture of the selected compounds were injected into the system. The total run time was $22 \mathrm{~min}$.

\section{Preparation of standard solutions}

Mixed stock solutions of twelve pharmaceutical standards $(200 \mu \mathrm{g} / \mathrm{mL})$ were prepared by dissolving $10 \mathrm{mg}$ with ultra-pure water/methanol $(50: 50, \mathrm{v} / \mathrm{v})$ in $50 \mathrm{~mL}$ volumetric flask. A stock solution of ciprofloxacin, which is insoluble in methanol, was dissolved in ultra-pure water $(200 \mu \mathrm{g} / \mathrm{mL})$ and stored in the refrigerator. Series of working standard solutions for the method development were prepared daily with a mixture of ultra-pure water/methanol (90:10, $\mathrm{v} / \mathrm{v})$.

\section{Preparation of tablet sample solutions}

For the preparation of the sample solutions used for method validation, an accurately weighed amount of powder equivalent to $10 \mathrm{mg}$ of each tablet was transferred completely to a $50 \mathrm{~mL}$ volumetric flask and dissolved with ultra-pure water/methanol $(50: 50, \mathrm{v} / \mathrm{v})$. The ciprofloxacin powdered tablet was dissolved in ultra-pure water only. All the tablet powders were sonicated in the solvent for about $30 \mathrm{~min}$ and then filtered through Whatman filter paper number 1 (110 $\mathrm{mm})$. The volume was adjusted to $50 \mathrm{~mL}$ followed by filtration through a $0.22 \mu \mathrm{m}$ membrane filter. Mixtures of series of sample solutions were prepared by dissolving with ultra-pure water and methanol $(90: 10, \mathrm{v} / \mathrm{v})$.

\section{Parameter optimization}

Separation in liquid chromatography is highly affected by different factors including mobile phase (both solvent type and composition), the addition of additives, absorption wavelength and mobile phase flow rate. Different solvents (water, acetonitrile and methanol) and additives (formic acid and acetic acid) were evaluated for the separation of thirteen pharmaceutical compounds. The mixed standard solution was scanned in the wavelength region of 190-400 nm for wavelength selection for proper separation. The effect of mobile phase flow rate was also investigated using a different flow rate of $0.6,1$ and $1.3 \mathrm{~mL} / \mathrm{min}$. The chromatographic parameters were evaluated by taking both the resolution and symmetry of the peaks into account.

\section{Validation of the analytical method}

The developed method for the determination of selected pharmaceuticals was evaluated as per the ICH Q2 [40] guidelines protocol for, linearity, sensitivity, precision, accuracy, specificity, robustness, and system suitability.

\section{RESULTS AND DISCUSSION}

\section{Mobile phase and additive selection}

The mobile phase was selected according to the physico-chemical properties of pharmaceutical drugs to provide good separation. Separation in liquid chromatography is highly affected by mobile phase, both solvent type and composition. Different solvents (water, acetonitrile and methanol) and additives (formic acid and acetic acid) were evaluated. From the examined mobile phase composition and additives, a combination of formic acid in water, acetonitrile and methanol resulted in the best resolution and a short run time. The effect of the concentration of 
formic acid in the water on separation was also examined and $0.1 \%$ formic acid yielded the best resolution between analytes. The composition of the solvent was evaluated by taking both the resolution and symmetry of the peak into account. The optimum mobile phase comprised three solvents. Separation of the analytes was accomplished over 22 min using gradient elution with A (water with $0.1 \%$ formic acid), B (acetonitrile) and $\mathrm{C}$ (methanol). The gradient was applied as follows: program, $90-50 \% \mathrm{~A}, 1-20 \% \mathrm{~B}$ and $9-30 \% \mathrm{C}(8 \mathrm{~min})$, held at $50 \% \mathrm{~A}, 20 \% \mathrm{~B}$ and $30 \%$

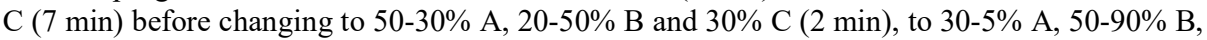
$30-5 \% \mathrm{C}(3 \mathrm{~min})$ and finally, to $5-90 \% \mathrm{~A}, 90-1 \% \mathrm{~B}$ and $5-9 \% \mathrm{C}$ (2 min).

\section{Wavelength selection}

The optimum wavelength should be the one which shows good absorbance for all the selected compounds. The mixed standard solution was scanned in the wavelength region of 190-400 nm. It is evident from Figure 1 that $250 \mathrm{~nm}$ yielded the largest overall relative peak height for all the analytes compared to those obtained at $240 \mathrm{~nm}, 270$ or $340 \mathrm{~nm}$. It should be noted that Table 1 shows that three compounds (amoxicillin, metronidazole and chloroquine) have a maximum UV absorption at $340 \mathrm{~nm}$ or close to $340 \mathrm{~nm}$. However, Figure 1 shows that only chloroquine had a good absorbance at $340 \mathrm{~nm}$ while amoxicillin and metronidazole do not had good absorbance at $340 \mathrm{~nm}$. This is because the absorbance of a compound depends on the type of solvent, concentration and molar absorptivity. This indicates that amoxicillin and metronidazole have smaller molar absorptivity in the solvent used. No absorption of amoxicillin and metronidazole at $340 \mathrm{~nm}$ may also be due effect of the other compounds present in the mixture. Therefore, 250 $\mathrm{nm}$ was selected as an optimum wavelength at which all the thirteen compounds showed good absorbance. It should also be noted that using a wavelength of $250 \mathrm{~nm}$ (the selected wavelength) would certainly diminish the sensitivity of the detector towards analytes with UV max above $300 \mathrm{~nm}$. Although this would not really matter for pharmaceutical products containing high concentrations of the active ingredient, since the analytes are easily detected, small differences in concentrations would not be picked up for these compounds.

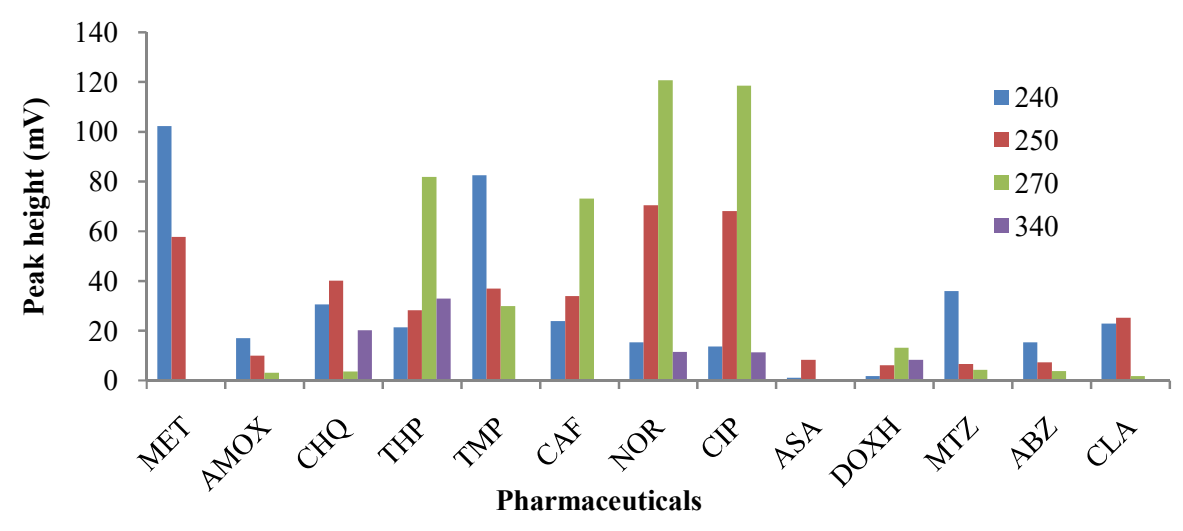

Figure 1. Detector response of 13 selected pharmaceutical drugs analysed using four different UV wavelengths to enable selection of the optimal wavelength.

Mobile phase flow rate optimization

The interaction of the compound with the stationary and the mobile phase affects the resolution of the peaks, in addition to the flow rate of the mobile phase. It was observed that the increase 
in flow rate $(1.3 \mathrm{~mL} / \mathrm{min})$ decreased the retention time of all analyte compounds, it adversely affected the resolution of some compounds. A faster mobile phase flow limits the interaction of analyte with the stationary phase. While decreasing the flow rate $(0.6 \mathrm{~mL} / \mathrm{min})$ increased the retention times and total run time, it caused and leads to broadening of the peaks and yielded poorly resolved peaks, compared to $1.0 \mathrm{~mL} / \mathrm{min}$ which was selected as optimum flow rate (Figure 2). In this study the first peak, which was due to the elution of metformin, was controlled by avoiding contamination with frequent injection in the system by running the blank after each run.

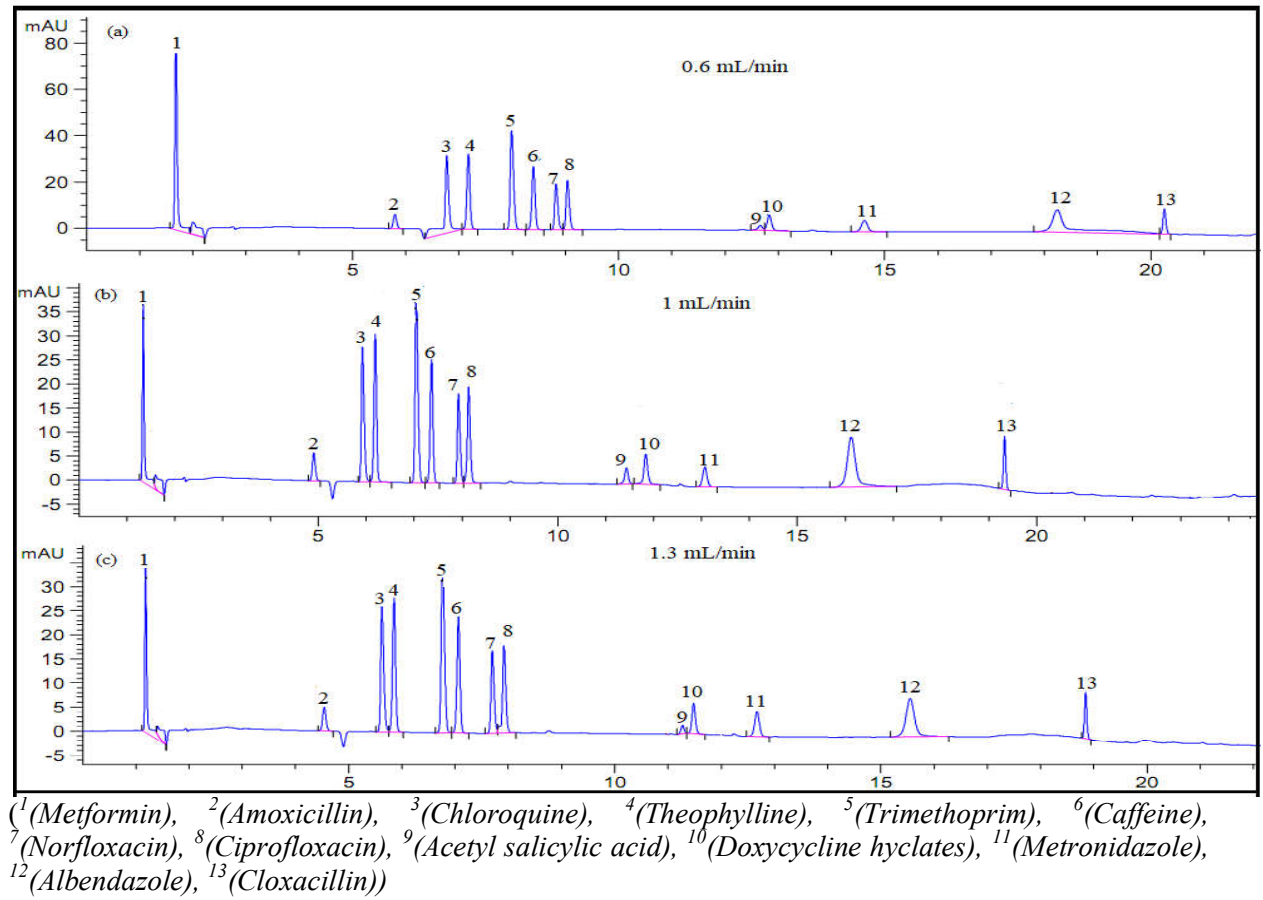

Figure 2. Chromatograms obtained using different mobile phase flow rates (a) $0.6 \mathrm{~mL} / \mathrm{min}$, (b) 1 $\mathrm{mL} / \mathrm{min}$ and (c) $1.3 \mathrm{~mL} / \mathrm{min}$.

Validation of the analytical method

\section{Linear range}

The ability of the assay to give data that is directly proportional to the concentration of analyte that the sample contains is referred to as linearity. Similarly, the range refers to the highest and lowest concentration of the analyte that can be detected by the detector of the method with an appropriate accuracy, precision, and linearity [41]. The linearity of the method measured as peak areas against the corresponding concentrations of the analyte compounds were evaluated using the correlation coefficients $\left(\mathrm{R}^{2}\right)$ as reported in (Table 2$)$. 
Table 2. Linear range, regression equation and correlation coefficient for each of the 13 selected pharmaceuticals when using the developed method.

\begin{tabular}{|l|c|c|c|}
\hline Pharmaceutical compound & $\begin{array}{c}\text { Linear range } \\
(\mu \mathrm{g} / \mathrm{mL})\end{array}$ & Regression equation & $\mathrm{R}^{2}$ \\
\hline Acetyl salicylic acid & $1.0-100$ & $\mathrm{y}=3.6181 \mathrm{x}+1.3002$ & 0.9998 \\
\hline Albendazole & $0.50-100$ & $\mathrm{y}=8.8529 \mathrm{x}+13.169$ & 0.9988 \\
\hline Amoxicillin & $2.5-100$ & $\mathrm{y}=2.4260 \mathrm{x}+0.2300$ & 0.9998 \\
\hline Caffeine & $0.50-100$ & $\mathrm{y}=10.167 \mathrm{x}+6.0284$ & 0.9996 \\
\hline Chloroquine & $0.50-100$ & $\mathrm{y}=11.150 \mathrm{x}+7.5555$ & 0.9997 \\
\hline Ciprofloxacin & $1.0-100$ & $\mathrm{y}=9.8126 \mathrm{x}+5.7892$ & 0.9987 \\
\hline Cloxacillin & $0.70-100$ & $\mathrm{y}=3.422 \mathrm{x}+2.7597$ & 0.9991 \\
\hline Doxycycline hyclates & $1.0-100$ & $\mathrm{y}=0.9325 \mathrm{x}+5.5146$ & 0.9987 \\
\hline Metformin & $0.50-100$ & $\mathrm{y}=9.0233 \mathrm{x}+7.2918$ & 0.9993 \\
\hline Metronidazole & $1.0-100$ & $\mathrm{y}=4.4886 \mathrm{x}+9.6939$ & 0.9985 \\
\hline Norfloxacin & $0.70-100$ & $\mathrm{y}=7.5441 \mathrm{x}+1.4492$ & 0.9998 \\
\hline Theophylline & $0.50-100$ & $\mathrm{y}=11.644 \mathrm{x}+8.8687$ & 0.9994 \\
\hline Trimethoprim & $0.25-100$ & $\mathrm{y}=16.536 \mathrm{x}+9.2685$ & 0.9997 \\
\hline
\end{tabular}

\section{Sensitivity}

The limits of detection (LOD) and limits of quantification (LOQ) for each of the analytes were calculated from the standard deviation of the response and slope of the calibration curve of pharmaceutical compounds using the formula as per ICH guideline, $3.3 \sigma / \mathrm{s}$ and $10 \sigma / \mathrm{s}$, respectively, where $\sigma$ is the standard deviation of the response and s the slope of the calibration curve. The results are reported in Table 3, which shows that the LODs ranged from 0.02-0.27 $\mu \mathrm{g} / \mathrm{L}$ and the LOQs from $0.08-0.91 \mu \mathrm{g} / \mathrm{L}$.

Table 3. LODs, LOQs and precision obtained for the method developed for the simultaneous determination of selected pharmaceutical compounds.

\begin{tabular}{|l|c|c|c|c|}
\hline Pharmaceutical compound & \multirow{2}{*}{$\begin{array}{c}\text { LOD } \\
(\mu \mathrm{g} / \mathrm{L})\end{array}$} & \multirow{2}{*}{$\begin{array}{c}\mathrm{LOQ} \\
\mathrm{n}\end{array}$} & & \multicolumn{2}{|c|}{ Precision \%RSD } \\
\cline { 4 - 5 } & & & $\begin{array}{c}\text { Repeatability } \\
(\% \mathrm{RSD}, \mathrm{n}=3)\end{array}$ & $\begin{array}{c}\text { Reproducibility } \\
(\% \mathrm{RSD}, \mathrm{n}=3)\end{array}$ \\
\hline Acetyl salicylic acid & 0.070 & 0.23 & 2.8 & 5.1 \\
\hline Albendazole & 0.040 & 0.15 & 1.7 & 4.3 \\
\hline Amoxicillin & 0.27 & 0.91 & 1.2 & 4.9 \\
\hline Caffeine & 0.020 & 0.08 & 1.1 & 2.0 \\
\hline Chloroquine & 0.030 & 0.12 & 1.4 & 3.3 \\
\hline Ciprofloxacin & 0.030 & 0.09 & 1.2 & 2.1 \\
\hline Cloxacillin & 0.16 & 0.53 & 1.3 & 3.9 \\
\hline Doxycycline hyclates & 0.16 & 0.54 & 3.1 & 5.2 \\
\hline Metformin & 0.15 & 0.33 & 3.0 & 3.9 \\
\hline Metronidazole & 0.10 & 0.58 & 1.3 & 4.1 \\
\hline Norfloxacin & 0.080 & 0.27 & 1.7 & 3.1 \\
\hline Theophylline & 0.050 & 0.16 & 1.4 & 5.3 \\
\hline Trimethoprim & 0.020 & 0.10 & 1.3 & \\
\hline
\end{tabular}

\section{Precision}

The precision of the developed method was evaluated by performing intra-day and inter-day precision studies using a concentration of $1 \mu \mathrm{g} / \mathrm{mL}$ of each analyte in solution. The measured peak areas were used to calculate the percent relative standard deviations (\%RSDs). Intra-day 
precision was carried out by analysing three replicates of a mixture of the standard pharmaceuticals on the same day. The measured peak areas were used to calculate the percentage relative standard deviations (\%RSDs). The inter-day precision study was performed on three consecutive days by analyzing the mixture of all thirteen pharmaceutical drugs in triplicate and the \% RSDs were calculated (Table 3). The result obtained for the precision study were regarded as acceptable for analysis, due to the small \% RSDs that ranged from 1.1-5.3\%, which were lower than the stipulated values of $15 \%$ [42].

Table 4. Results of the recovery studies of the developed HPLC method.

\begin{tabular}{|c|c|c|c|c|c|}
\hline \multirow{2}{*}{$\begin{array}{l}\text { Pharmaceutical } \\
\text { compound }\end{array}$} & \multicolumn{3}{|c|}{ Pre-analyzed standard } & \multicolumn{2}{|c|}{ Pre-analyzed tablet } \\
\hline & $\begin{array}{l}\text { Spiked } \\
\text { amount }\end{array}$ & $\begin{array}{c}\text { Recovery } \\
(\%)\end{array}$ & $\begin{array}{c}\text { Mean } \\
\text { recovery } \pm \mathrm{SD}\end{array}$ & $\begin{array}{c}\text { Recovery } \\
(\%)\end{array}$ & $\begin{array}{c}\text { Mean } \\
\text { recovery } \pm \mathrm{SD}\end{array}$ \\
\hline \multirow{3}{*}{$\begin{array}{l}\text { Acetyl salicylic } \\
\text { acid }\end{array}$} & $50 \%$ & 86.8 & \multirow{3}{*}{$86.3 \pm 1.0$} & 89.4 & \multirow{3}{*}{$90.9 \pm 10$} \\
\hline & $100 \%$ & 85.2 & & 81.4 & \\
\hline & $150 \%$ & 87.0 & & 102 & \\
\hline \multirow{3}{*}{ Albendazole } & $100 \%$ & 89.7 & \multirow{3}{*}{$93.8 \pm 7.7$} & 89.2 & \multirow{3}{*}{$95.1 \pm 5.2$} \\
\hline & $150 \%$ & 103 & & 97.8 & \\
\hline & $150 \%$ & 89.0 & & 98.5 & \\
\hline \multirow{3}{*}{ Amoxicillin } & $50 \%$ & 88.9 & \multirow{3}{*}{$86.8 \pm 1.8$} & 99.6 & \multirow{3}{*}{$97.0 \pm 3.5$} \\
\hline & $100 \%$ & 86.0 & & 93.0 & \\
\hline & $150 \%$ & 85.5 & & 98.5 & \\
\hline \multirow{3}{*}{ Caffeine } & $50 \%$ & 92.5 & \multirow{3}{*}{$93.5 \pm 1.7$} & 83.1 & \multirow{3}{*}{$91.9 \pm 8.2$} \\
\hline & $100 \%$ & 92.6 & & 99.4 & \\
\hline & $150 \%$ & 95.6 & & 93.1 & \\
\hline \multirow{3}{*}{ Chloroquine } & $50 \%$ & 88.7 & \multirow{3}{*}{$87.9 \pm 2.4$} & 93.7 & \multirow{3}{*}{$94.9 \pm 11$} \\
\hline & $100 \%$ & 85.2 & & 107 & \\
\hline & $150 \%$ & 89.9 & & 83.9 & \\
\hline \multirow{3}{*}{ Ciprofloxacin } & $50 \%$ & 89.9 & \multirow{3}{*}{$102 \pm 10$} & 89.4 & \multirow{3}{*}{$97.4 \pm 7.0$} \\
\hline & $100 \%$ & 105 & & 103 & \\
\hline & $150 \%$ & 111 & & 100 & \\
\hline \multirow{3}{*}{ Cloxacillin } & $50 \%$ & 96.0 & \multirow{3}{*}{$92.2 \pm 3.5$} & 110 & \multirow{3}{*}{$106 \pm 4.0$} \\
\hline & $100 \%$ & 89.0 & & 104 & \\
\hline & $150 \%$ & 91.6 & & 103 & \\
\hline \multirow{3}{*}{ Metformin } & $50 \%$ & 89.4 & \multirow{3}{*}{$87.5 \pm 1.7$} & 105 & \\
\hline & $100 \%$ & 87.2 & & 104 & $105 \pm 1.7$ \\
\hline & $150 \%$ & 85.9 & & 107 & \\
\hline Doxycycline & $50 \%$ & 108 & & 117 & \\
\hline hyclates & $100 \%$ & 93.7 & $100 \pm 7.6$ & 95.2 & $101 \pm 9.6$ \\
\hline & $150 \%$ & 97.9 & & 94.7 & \\
\hline & $50 \%$ & 94.8 & & 115 & \\
\hline Metronidazole & $100 \%$ & 113 & $101 \pm 10$ & 90.1 & $104 \pm 12$ \\
\hline & $150 \%$ & 95.5 & & 106 & \\
\hline & $50 \%$ & 85.6 & & 98 & \\
\hline Norfloxacin & $100 \%$ & 96.3 & $95.3 \pm 9.2$ & 109 & $99.6 \pm 9.2$ \\
\hline & $150 \%$ & 104 & & 91.3 & \\
\hline Theophylline & $50 \%$ & 85.2 & & 103 & \\
\hline & $100 \%$ & 87.6 & $87.9 \pm 2.8$ & 105 & $101 \pm 6.1$ \\
\hline & $150 \%$ & 90.9 & & 93.8 & \\
\hline & $50 \%$ & 86.5 & & 108 & \\
\hline Trimethoprim & $100 \%$ & 85.4 & $86.3 \pm 0.8$ & 102 & $98.5 \pm 11$ \\
\hline & $150 \%$ & 86.9 & & 85.8 & \\
\hline
\end{tabular}


Accuracy

To study the accuracy of the proposed method, recovery studies were carried out by applying standard addition at three different levels. A known amount of the mixture of pharmaceutical compounds $(50 \%, 100 \%$ and $150 \%)$ of $10 \mathrm{mg} / \mathrm{L}$ was added to a pre-analyzed standard and sample solution. The percentage recoveries were calculated as reported in Table 4. Recoveries ranged from $86.0-102 \%$ for pure compounds and from $90.9-106 \%$ for tablet dosage forms, which are within the acceptable range [42]. The preparation of the solution and the ingredients other than the active compounds in the marketed tablet might be the reason for the difference in the recovery.

\section{Specificity}

The specificity of the developed HPLC method was established by injecting the blank (solvent) and placebo solution without active pharmaceutical ingredient, into the HPLC system using the optimized conditions. The representative chromatogram of blank and placebo is shown in Figure 3 (a) and (b), respectively. No peaks were detected at the retention times corresponding to any of the target analytes considered in this study.

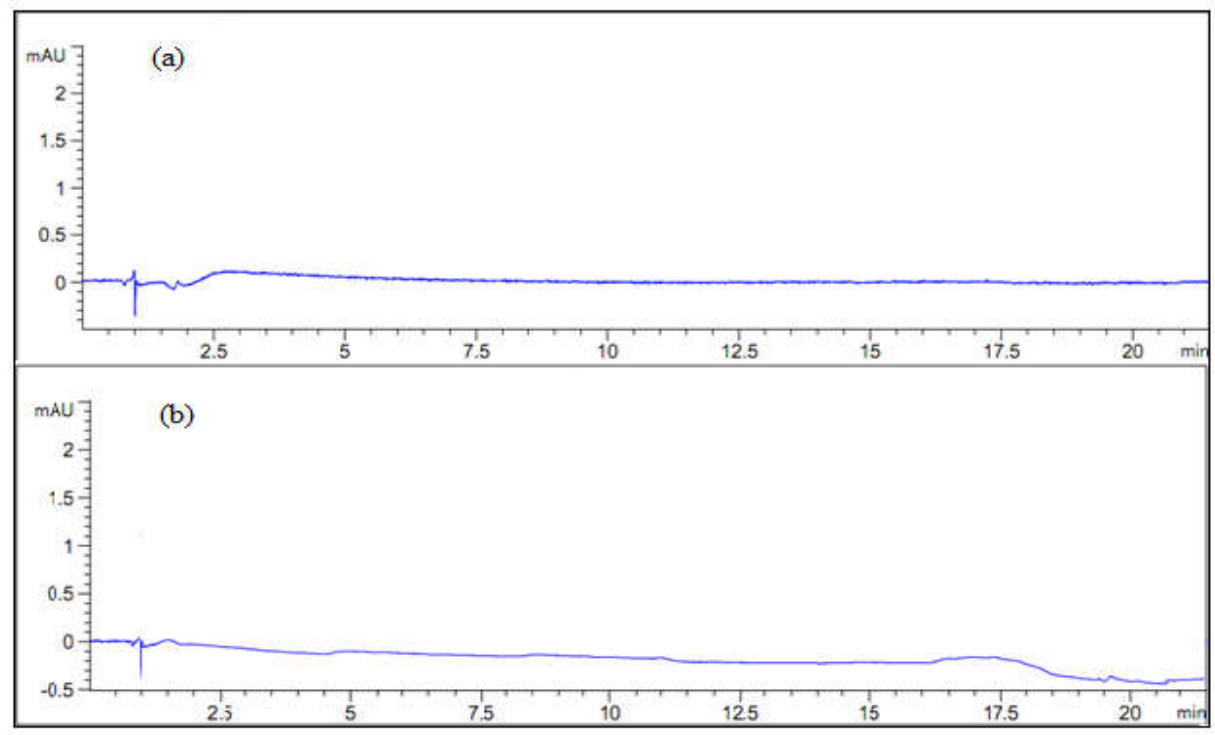

Figure 3. Chromatogram of the blank solvent (a) and placebo solution (b) using the developed method.

\section{Robustness}

The robustness of an analytical procedure refers to its capability to remain unaffected by small, but deliberate variations in method parameters [43] and provides an indication of its reliability during application. Robustness of the developed method was investigated after minor modifications of conditions including changes to the flow rate of the mobile phase, percent of additive (formic acid) in the mobile phase, and detector wavelength for absorption. The results 
(Table 5) revealed that the developed method is robust, and the peaks are well separated and elute with acceptable symmetry and resolution.

Table 5. Results of the method robustness tests.

\begin{tabular}{|c|c|c|c|c|c|c|c|c|c|c|}
\hline \multirow[t]{3}{*}{ Compounds } & \multicolumn{10}{|c|}{ Parameters changed for robustness study } \\
\hline & \multicolumn{4}{|c|}{ Flow rate $(\mathrm{mL} / \mathrm{min})$} & \multicolumn{3}{|c|}{ Wavelength $(\mathrm{nm})$} & \multicolumn{3}{|c|}{$\%$ Formic acid } \\
\hline & & 0.8 & 1.0 & 1.2 & 248 & 250 & 252 & 0.05 & 0.1 & 0.15 \\
\hline \multirow[t]{3}{*}{ Albendazole } & $\begin{array}{l}\text { Peak } \\
\text { symmetry }\end{array}$ & 1.116 & 0.913 & 0.879 & 0.379 & 0.913 & 0.927 & 1.077 & 0.913 & 0.919 \\
\hline & $\%$ RSD & 0.362 & 1.731 & 3.267 & 1.971 & 1.731 & 2.962 & 0.166 & 1.731 & 2.146 \\
\hline & Rt (min) & 16.03 & 16.17 & 15.55 & 16.07 & 16.17 & 16.08 & 16.18 & 16.17 & 16.62 \\
\hline \multirow[t]{3}{*}{ Amoxicillin } & $\begin{array}{l}\text { Peak } \\
\text { symmetry }\end{array}$ & 0.883 & 0.218 & 0.911 & 0.585 & 0.218 & 0.47 & 0.903 & 0.218 & 0.837 \\
\hline & $\%$ RSD & 0.557 & 1.205 & 3.566 & 0.838 & 1.205 & 3.077 & 2.722 & 1.205 & 2.939 \\
\hline & Rt (min) & 5.344 & 4.910 & 4.541 & 4.823 & 4.910 & 4.812 & 4.584 & 4.910 & 3.758 \\
\hline \multirow[t]{3}{*}{$\begin{array}{l}\text { Acetyl salicylic } \\
\text { acid }\end{array}$} & $\begin{array}{l}\text { Peak } \\
\text { symmetry }\end{array}$ & 1.038 & 0.995 & 1.091 & 1.26 & 0.995 & 0.782 & 0.912 & 0.995 & 1.100 \\
\hline & $\%$ RSD & 4.641 & 2.778 & 2.158 & 1.794 & 2.778 & 2.963 & 3.608 & 2.778 & 0.307 \\
\hline & Rt (min) & 11.53 & 11.51 & 11.11 & 11.42 & 11.51 & 11.50 & 11.16 & 11.51 & 11.12 \\
\hline \multirow[t]{3}{*}{ Caffeine } & $\begin{array}{l}\text { Peak } \\
\text { symmetry }\end{array}$ & 0.960 & 0.995 & 0.988 & 0.988 & 0.995 & 0.995 & 0.611 & 0.995 & 1.005 \\
\hline & $\%$ RSD & 3.057 & 1.142 & 4.339 & 2.050 & 1.142 & 0.544 & 3.629 & 1.142 & 2.204 \\
\hline & $\mathrm{Rt}(\mathrm{min})$ & 7.731 & 7.417 & 7.064 & 7.032 & 7.417 & 7.293 & 7.162 & 7.417 & 7.167 \\
\hline \multirow[t]{3}{*}{ Chloroquine } & $\begin{array}{l}\text { Peak } \\
\text { symmetry }\end{array}$ & 1.735 & 0.676 & 0.630 & 1.46 & 0.676 & 1.592 & 0.650 & 0.676 & 0.393 \\
\hline & $\%$ RSD & 3.125 & 1.430 & 3.110 & 2.478 & 1.430 & 0.878 & 0.660 & 1.430 & 1.257 \\
\hline & $\mathrm{Rt}(\mathrm{min})$ & 6.241 & 5.900 & 5.623 & 5.634 & 5.900 & 5.476 & 5.626 & 5.900 & 4.940 \\
\hline \multirow[t]{3}{*}{ Ciprofloxacin } & $\begin{array}{l}\text { Peak } \\
\text { symmetry }\end{array}$ & 0.770 & 0.717 & 0.866 & 0.913 & 0.717 & 0.908 & 0.897 & 0.717 & 0.630 \\
\hline & $\%$ RSD & 2.564 & 1.198 & 2.894 & 3.398 & 1.198 & 0.676 & 3.994 & 1.198 & 1.684 \\
\hline & $\mathrm{Rt}$ (min) & 8.308 & 8.166 & 7.918 & 8.008 & 8.166 & 8.014 & 7.700 & 8.166 & 7.518 \\
\hline \multirow[t]{3}{*}{ Cloxacillin } & $\begin{array}{l}\text { Peak } \\
\text { symmetry }\end{array}$ & 0.911 & 0.925 & 0.912 & 0.270 & 0.925 & 0.968 & 0.948 & 0.925 & 0.856 \\
\hline & $\%$ RSD & 3.832 & 1.323 & 3.909 & 2.008 & 1.323 & 0.785 & 3.578 & 1.323 & 2.096 \\
\hline & $\mathrm{Rt}(\mathrm{min})$ & 19.278 & 19.39 & 18.85 & 19.03 & 19.39 & 18.99 & 19.23 & 19.393 & 19.16 \\
\hline \multirow[t]{3}{*}{ Metformin } & $\begin{array}{l}\text { Peak } \\
\text { symmetry }\end{array}$ & 0.672 & 0.503 & 0.515 & 1.002 & 0.503 & 0.999 & 0.406 & 0.503 & 0.721 \\
\hline & $\%$ RSD & 2.818 & 3.020 & 1.961 & 1.961 & 3.020 & 3.030 & 1.171 & 3.020 & 0.969 \\
\hline & Rt (min) & 1.635 & 1.334 & 1.185 & 1.333 & 1.334 & 1.332 & 1.348 & 1.334 & 1.333 \\
\hline \multirow[t]{3}{*}{$\begin{array}{l}\text { Doxycycline } \\
\text { hyclates }\end{array}$} & $\begin{array}{l}\text { Peak } \\
\text { symmetry }\end{array}$ & 0.844 & 0.859 & 0.851 & 0.659 & 0.859 & 0.740 & 0.247 & 0.859 & 0.846 \\
\hline & $\%$ RSD & 4.545 & 3.104 & 3.040 & 4.140 & 3.104 & 2.433 & 3.101 & 3.104 & 2.674 \\
\hline & Rt (min) & 11.76 & 11.82 & 11.56 & 11.52 & 11.82 & 11.45 & 11.78 & 11.82 & 11.35 \\
\hline \multirow[t]{3}{*}{ Metronidazole } & $\begin{array}{l}\text { Peak } \\
\text { symmetry }\end{array}$ & 1.019 & 0.953 & 1.009 & 0.771 & 0.953 & 1.245 & 0.948 & 0.953 & 1.154 \\
\hline & $\%$ RSD & 1.742 & 1.294 & 0.754 & 2.286 & 1.294 & 3.116 & 3.838 & 1.294 & 0.881 \\
\hline & $\mathrm{Rt}$ (min) & 13.11 & 13.19 & 12.67 & 13.04 & 13.19 & 13.01 & 12.24 & 13.19 & 12.33 \\
\hline \multirow[t]{3}{*}{ Norfloxacin } & $\begin{array}{l}\text { Peak } \\
\text { symmetry }\end{array}$ & 0.780 & 0.714 & 0.712 & 1.037 & 0.714 & 1.026 & 0.671 & 0.714 & 0.547 \\
\hline & $\%$ RSD & 1.890 & 1.713 & 4.006 & 1.389 & 1.713 & 1.949 & 2.163 & 1.713 & 0.081 \\
\hline & $\operatorname{Rt}(\min )$ & 8.114 & 7.960 & 7.699 & 7.654 & 7.960 & 7.556 & 7.494 & 7.960 & 7.269 \\
\hline Theophylline & $\begin{array}{l}\text { Peak } \\
\text { symmetry }\end{array}$ & 0.963 & 0.942 & 1.003 & 0.792 & 0.942 & 0.783 & 0.637 & 0.942 & 0.952 \\
\hline
\end{tabular}

Bull. Chem. Soc. Ethiop. 2021, 35(1) 


\begin{tabular}{|l|l|l|l|l|l|l|l|l|l|l|}
\hline \multirow{5}{*}{ Trimethoprim } & \% RSD & 1.141 & 1.414 & 2.710 & 1.916 & 1.414 & 1.068 & 2.850 & 1.414 & 0.816 \\
\cline { 2 - 11 } & Rt (min) & 6.616 & 6.242 & 5.853 & 5.934 & 6.242 & 6.103 & 5.950 & 6.242 & 5.972 \\
\hline & $\begin{array}{l}\text { Peak } \\
\text { symmetry }\end{array}$ & 0.772 & 0.691 & 0.701 & 1.021 & 0.691 & 1.047 & 0.963 & 0.691 & 0.499 \\
\cline { 2 - 11 } & \% RD & 2.578 & 1.269 & 2.277 & 3.044 & 1.269 & 0.544 & 1.292 & 1.269 & 1.263 \\
\cline { 2 - 11 } & Rt (min) & 7.348 & 7.038 & 6.764 & 7.010 & 7.038 & 7.021 & 6.751 & 7.038 & 6.371 \\
\hline
\end{tabular}

System suitability

The system suitability test of a chromatographic method is used to verify that the chromatographic system is adequate for application to samples. The parameters considered for this test include retention time, resolution (to the adjacent peak); peak symmetry and number of theoretical plates. These parameters were investigated using the optimized chromatographic conditions. The results (Table 6) reflect good performance and acceptable levels for all the selected analytes.

Table 6. System suitability results determined for the developed chromatographic method.

\begin{tabular}{|l|c|c|c|c|}
\hline Pharmaceutical compound & $\begin{array}{c}\text { Retention time } \\
(\mathrm{min})\end{array}$ & Resolution & $\begin{array}{c}\text { Peak } \\
\text { symmetry }\end{array}$ & $\begin{array}{c}\text { Theoretical } \\
\text { plates (N) }\end{array}$ \\
\hline Acetyl salicylic acid & 11.5 & 3.7 & 0.995 & 341762 \\
\hline Albendazole & 16.2 & 13 & 0.953 & 28382 \\
\hline Amoxicillin & 4.8 & 9.0 & 0.218 & 18916 \\
\hline Caffeine & 7.4 & 8.5 & 0.955 & 212283 \\
\hline Chloroquine & 5.9 & 5.0 & 0.676 & 139880 \\
\hline Ciprofloxacin & 8.2 & 47 & 0.717 & 262543 \\
\hline Cloxacillin & 19.4 & - & 0.925 & 2071273 \\
\hline Metformin & 1.3 & 30 & 0.503 & 13950 \\
\hline Doxycycline hyclates & 11.8 & 14.5 & 0.859 & 311071 \\
\hline Metronidazole & 13.2 & 21 & 0.953 & 251295 \\
\hline Norfloxacin & 7.6 & 3.2 & 0.714 & 250709 \\
\hline Theophylline & 6.2 & 12.5 & 0.942 & 170141 \\
\hline Trimethoprim & 7.0 & 5.8 & 0.691 & 174425 \\
\hline
\end{tabular}

\section{CONCLUSION}

A simple, accurate, precise and robust HPLC method has been developed for the determination of thirteen selected pharmaceutical drugs in bulk and marketed tablet dosage form using a single optimized condition. The developed method was validated using ICH guidelines, which proves the reliability of the proposed method. The accuracy of the method was validated by percentage recovery and found to be in the acceptable range. The system suitability parameters were within limit, hence it was concluded that all the systems were suitable to perform further analysis. The development of such an analytical method has many advantages, since different products can be analysed in sequence without changing the instrumental conditions. This is a cost-effective approach for laboratories that lack highly specialized state-of-the-art instrumentation, since it streamlines the laboratory workflow. As new samples come in for quality control, they can be analyzed without any changes to the instrumental conditions. 


\section{ACKNOWLEDGEMENTS}

The authors acknowledge the Organization for Women Scientists for Developing World (OWSD Postgraduate Fellowship) and SIDA (Swedish International Development Cooperation Agency) for funding this research and the University of Witwatersrand, Johannesburg, South Africa, for access to their laboratory.

\section{REFERENCES}

1. Bartha, B.; Huber, C.; Schroder, P. Uptake and metabolism of diclofenac in Typha latifolia how plants cope with human pharmaceutical pollution. Plant Sci. 2014, 227, 12-20.

2. Gumbi, B.P.; Moodley, B.; Birungi, G.; Ndungu, P.G. Detection and quantification of acidic drug residues in South African surface water using gas chromatography-mass spectrometry. Chemosphere 2017, 168, 1042-1050.

3. Ngumba, E.; Gachanja, A.; Tuhkanen, T. Occurrence of selected antibiotics and antiretroviraldrugs in Nairobi River Basin, Kenya. Sci. Total Environ. 2016, 539, 206213.

4. Elhag, D.E.; Abdallah, B.S.; Hassan, M.; Suliman, A. ESI-LC/MS method development andvalidation for the determination of some selected antibiotics in hospital wastewater. Pharm. Anal. Acta 2018, 9, 1-6.

5. Svetlana, P.K. Quantitative determination of amoxicillin trihydrate in medicalforms using kinetic method. J. Chem. Pharm. Res. 2014, 6, 1120-1125.

6. Varak, M.; Ebrahimi, M. Preconcentration and determination of ciprofloxacin with solidphase microextraction and silica-coated magnetic nanoparticles modified with salicylic acid by UV-Vis spectrophotometry. Eurasian J. Anal. Chem. 2018, 13, 1-12.

7. Patel, N.; Contractor, P.; Keshrala, R.; Patel, P.R.; Shridhar, B. Development and validation of a stability-indicating RP-UPLC method for determination of cloxacillin sodium in its bulk form and formulation. J. Chromatogr. Sci. 2015, 53, 903-908.

8. Abbas, R.F.; Hami, H.K.; Mahdi, N.I. Removal of doxycycline hyclate by adsorption onto cobalt oxide at three different temperatures: Isotherm, thermodynamic and error analysis. Int. J. Environ. Sci. Technol. 2018, 1-8.

9. Zhao, S.; Zhao, H.; Zhu, H.; Li, C.; Lu, X.; Bi, S. Determination of norfloxacin and ciprofloxacin inchicken meat based on matrix solid-phase dispersion extraction and capillary zone electrophoresis. J. Chem. 2014, 1-5.

10. Amin, A.S.; Shahat, M.F.; Edeen, R.E.; Meshref, M.A. Comparison of ion-pairing and reversed phase liquid chromatography in determination of sulfamethoxazole and trimethoprim. Anal. Lett. 2008, 41, 1878-1894.

11. Elkhoudary, M.M.; Abdel Salam, R.A.; Hadad, G.M. Development and optimization of HPLC analysis of metronidazole, diloxanide, spiramycin and cliquinol in pharmaceutical dosage forms using experimental design. J. Chromatogr. Sci. 2016, 54, 1701-1712.

12. Yadav, P.; Singh, R. A review on anthelmintic drugs and their future scope. Int. J. Pharm. Pharm. Sci. 2011, 3, 17-21.

13. Sowjanya, S.; Devadasu, C. Development of RP-HPLC method for the simultaneous quantitation of levamisole and albendazole: Application to assay validation. Int. J. Anal. Chem. 2018, 1-10.

14. Qarah A.S.N.; Basavaiah, K.; Swamy, N. Sensitive and selective extraction-free spectrophotometric assay of chloroquine phosphate in pharmaceuticals based on ionpair reaction with bromocresol green and bromocresol purple. Pharm. Anal. Acta 2017, 8, 19. 
15. de Aguiar, J.L.N.; Leandro, K.C.; Abrantes, S.M.P.; Albert, A.L.M. Development of a new analytical method for determination ofacetylsalicylic and salicylic acids in tablets by reversed phase liquid chromatography. Braz. J. Pharm. Sci. 2009, 45, 723-727.

16. Hobl, E.; Jilma, B.; Ebner, J.; Schmid, R.W. Simultaneous determination of acetylsalicylic acid and salicylic acid in human plasma byisocratic high-pressure liquid chromatographywith post-column hydrolysis and fluorescence detection. Biomed. Chromatogr. 2012, 27, 695-698.

17. Chowdhury, S.R.; Maleque, M.; Shihan, M.H. Development and validation of a simple RPHPLC method for determination of caffeine in pharmaceutical dosage forms. Asian J. Pharm. Anal. 2012, 2, 1-4.

18. Sayeed, M.A.; Habib, R.; Rahman, M.; Banna, H.A.; Rana, S. In vitro study on the interaction of ketotifen fumarate withanhydrous theophylline. Braz. J. Pharm. Sci. 2012, 48, 211-216.

19. Silpavathi, L.; Das, M.K. A Non-aqueous titrimetry and UV spectrophotometric study of metformin hydrochloride marketed tablets. J. Chem. Pharm. Sci. 2015. 8, 128-130.

20. Bendz, D.; Paxeus, N.A.; Ginn, T.R.; Loge, F.J. Occurrence and fate of pharmaceutically active compounds in the environment, a case study: Hoje River in Sweden. J. Hazard. Mater. 2005, 122, 195-204.

21. Iglesias, A.; Nebot, C.; Vázquez, B.; Coronel-Olivares, C.; Abuín, F.; Cepeda, A. Monitoring the presence of 13 active compounds in surface water collected from rural areas in Northwestern Spain. Int. J. Environ. Res. Public Health 2014, 11, 5251-5272.

22. Sarode, S.K.; Pise, S.T.; Dhore, P.; Mundhada, D.R.; Bhaskaran, S. Development of analytical method for simultaneous estimation of amoxicillin and carbocisteine in solid dosage form by RP-HPLC. BioMedRx. 2013, 1, 360-362.

23. Ahmed, D.A.; Abdel-Aziz, O.; Abdel-Ghany, M.; Weshahy, S.A. Stability indicating determination of Albendazole in bulk drug and pharmaceutical dosage form by chromatographic and spectrophotometric methods. Future J. Pharm. Sci. 2018, 4, 161-165.

24. Miranda, T.A.; Silva, P.H.; Pianetti, G.A.; Cesar, I.C. Simultaneous quantitation of chloroquine andprimaquine by UPLC-DAD and comparison with a HPLC-DAD method. Malar. J. 2015, 14, 1-7.

25. Radi, M.; Ramli, Y.; Karbane, M.E.; Marzak, S.; Bougrin, K. Validation of a method for simultaneous determination of acetaminophen and caffeine by HPLC in different pharmaceutical forms: Tablet, capsule and sachet. J. Mater. Environ. Sci. 2016, 7, 46084613.

26. Umapathi, P.; Ayyappan, J.; Quine, S.D. Quantitative determination of metformin hydrochloride in tablet formulation containing croscarmellose sodium as disintegrant by HPLC and UV-spectrophotometry. Trop. J. Pharm. Res. 2012, 11, 107-116.

27. Kanakal, M.M.; Majid, A.S.A.; Sattar, M.Z.A.; Ajmi, N.S.; Majid, A.S.A. Buffer-free high performance liquid chromatography method for the determination of theophylline in pharmaceutical dosage forms. Trop. J. Pharm. Res. 2014, 13, 149-153.

28. Gezahegn, T.; Tegegne, B.; Zewge, F.; Chandravanshi, B.S. Salting-out assisted liquidliquid extraction for the determination of ciprofloxacin residues in water samples by high performance liquid chromatography-diode array detector. BMC Chem. 2019, 13, 1-10.

29. Naguib, I.A.; Abdelaleem, E.A.; Zaazaa, H.E.; Hussein, E.A.; Alsalahat, I. Development and validation of spectrophotometric methods for the determination of amoxicillin trihydrate and dicloxacillin sodium in their binary mixture. Anal. Chem. Lett. 2018, 8, 844-861.

30. Shailesh, J.W.; Shailesh; L.P.; Shivraj, S.S.; Supriya S.K.; Sima, S.L.; Puranik, P.M. Stability indicating assay methods for simultaneous estimation ofamoxicillin trihydrate and cloxacillin sodium in combined capsule dosage form by UV-spectrophotometric method. $J$. Biomed. Pharm. Sci. 2017, 4, 858-864. 
31. Palamy, S.; Ruengsitagoon, W. Reverse flow injection spectrophotometric determination of ciprofloxacin in pharmaceuticals using iron from soil as a green reagent. Spectrochim. Acta A Mol. Biomol. Spectrosc. 2018, 190, 129-134.

32. Adegoke, O.A.; Babalola, C.P.; Kotila, O.A.; Obuebhor, O. Simultaneous spectrophotometric determination of trimethoprim and sulphamethoxazole following charge-transfer complexation with chloranilic acid. Arab. J. Chem. 2017, 10, 3848-3860.

33. Kanakapura, B.; Penmatsa, V.K.; Umakanthappa, C. Simple and selective spectrophotometric assay of chloroquine inpharmaceuticals using two nitrophenols as chromogenic agents. J. Pharm. Biol. Sci. 2016, 11, 29-40.

34. Ashour, S.; Kabbani, R.; Direct spectrophotometric determination of metformin hydrochloride in pure form and in drug formulations. Anal. Lett. 2003, 36, 361-370.

35. Yilmaz, S.; Baltaoglu, E.; Saglikoglu, G.; Yagmur, S.; Polat, K.; Sadikoglu, M. Electroanalytical determination of metronidazole in tablet dosage form. J. Serbian Chem. Soc. 2013, 78, 295-302.

36. Mekassa, B.; Tessema, M.; Chandravanshi, B.S. Simultaneous determination of caffeine and theophylline using square wave voltammetry at poly(l-aspartic acid)/functionalized multiwalled carbon nanotubes composite modified electrode. Sens. Bio-Sensing Res. 2017, 16, 46-54.

37. de Macedo, I.Y.L.; Garcia, L.F.; de Souza, A.R.; da Silva, A.M.L. Differential pulse voltammetric determination of albendazole and mebendazole in pharmaceutical formulations based on modified sonogel carbon paste electrodes with perovskite-type $\mathrm{LaFeO}_{3}$ nanoparticles. Int. J. Electrochem. Sci. 2016, 163, 428-434.

38. Cofan, C.; Radovan, C. Anodic determination of acetylsalicylic acid at a mildly oxidized boron-doped diamond electrode in sodium sulphate medium. Int. J. Electrochem. Sci. 2011, $1-9$.

39. Shao, X.; Liu, H.; Gao, X.; Chen, W.; Song, Z. Determination of norfloxacin in pharmaceuticals, human serum, and urine using a luminol-dissolved oxygen chemiluminescence system. Chem. Papers 2007, 61, 353-358.

40. ICH, Q.R. The international council for harmonisation of technical requirements for pharmaceuticals for human use (ICH). Text and methodology Q2(R1). Geneva, Swizerland IFPMA, 2005.

41. Sutariya, V.; Wehrung, D.; Geldenhuys, W.J. Development and validation of a novel RPHPLC method for the analysis of reduced glutathione. J. Chromatogr. Sci. 2012, 50, 271276.

42 UNODC. Guidance for the Validation of Analytical Methodology and Calibration of Equipment used for Testing of Illicit Drugs in Seized Materials and Biological Specimens, United Nation New York, 2009, 1-67. https://www.unodc.org/ documents/scientific/ validation. pdf (18 January 2021).

43. Shah, P.; Pandya, T.; Gohel, M.; Thakkar, V. Development and validation of HPLC method for simultaneous estimation of rifampicin and ofloxacin using experimental design. $J$. Taibah Univ. Sci. 2018, 13, 146-154. 